BMJ Open

Diabetes

Research

\& Care

\title{
Outcomes after surgery in patients with diabetes who used metformin: a retrospective cohort study based on a real-world database
}

\author{
Chao-Shun Lin, ${ }^{1,2,3}$ Chuen-Chau Chang, ${ }^{1,2,3}$ Chun-Chieh Yeh, ${ }^{4,5}$ Yi-Cheng Chang, ${ }^{6}$ \\ Ta-Liang Chen, ${ }^{2,3,7}$ Chien-Chang Liao (1) 1,2,3,8,9
}

\begin{abstract}
To cite: Lin C-S, Chang C-C, Yeh C-C, et al. Outcomes after surgery in patients with diabetes who used metformin: a retrospective cohort study based on a real-world database. BMJ Open Diab Res Care 2020;8:e001351. doi:10.1136/ bmjdrc-2020-001351
\end{abstract}

- Supplemental material is published online only. To view please visit the journal online (http://dx.doi.org/10.1136/ bmjdrc-2020-001351).

T-LC and C-CL contributed equally.

Received 12 March 2020 Revised 6 August 2020 Accepted 15 August 2020
Check for updates

\section{(C) Author(s) (or their} employer(s)) 2020. Re-use permitted under CC BY-NC. No commercial re-use. See rights and permissions. Published by BMJ.

For numbered affiliations see end of article.

\section{Correspondence to}

Professor Chien-Chang Liao; jacky48863027@yahoo.com.tw

\section{ABSTRACT}

Introduction Limited information was available regarding the perioperative outcomes in patients with and without use of metformin. This study aims to evaluate the complications and mortality after major surgery in patients with diabetes who use metformin.

Research design and methods Using a real-world database of Taiwan's National Health Insurance from 2008 to 2013, we conducted a matched cohort study of 91356 patients with diabetes aged $>20$ years who used metformin and later underwent major surgery. Using a propensity score-matching technique adjusted for sociodemographic characteristics, medical condition, surgery type, and anesthesia type, 91356 controls who underwent surgery but did not use metformin were selected. Logistic regression was used to calculate the ORs with 95\% Cls for postoperative complications and 30-day mortality associated with metformin use.

Results Patients who used metformin had a lower risk of postoperative septicemia (OR $0.94,95 \% \mathrm{Cl} 0.90$ to 0.98 ), acute renal failure (OR $0.87,95 \% \mathrm{Cl} 0.79$ to 0.96$)$, and 30 -day mortality (OR $0.79,95 \% \mathrm{Cl} 0.71$ to 0.88 ) compared with patients who did not use metformin, in both sexes and in every age group. Metformin users who underwent surgery also had a decreased risk of postoperative intensive care unit admission (OR $0.60,95 \% \mathrm{Cl} 0.59$ to $0.62)$ and lower medical expenditures $(p<0.0001)$ than non-use controls.

Conclusions Among patients with diabetes, those who used metformin and underwent major surgery had a lower risk of complications and mortality compared with non-users. Further randomized clinical trials are needed to show direct evidence of how metformin improves perioperative outcomes.

\section{INTRODUCTION}

The disease burden related to diabetes is rising, ${ }^{1}$ and it was estimated in 2017 that there are 451 million people with diabetes worldwide. $^{2}$ Diabetes causes multisystem complications, including retinopathy, nephropathy, neuropathy, ischemic heart disease, stroke and peripheral vascular disease. Diabetes and its complications, associated mortality, reduced life expectancy, and financial costs

\section{Significance of this study}

What is already known about this subject?

- Patients with diabetes had more postoperative complications and higher mortality than people without diabetes.

What are the new findings?

- Metformin use was associated with a reduced risk of 30-day in-hospital mortality and postoperative complications in patients with diabetes.

- The use of metformin was strongly associated with reduced use of intensive care and less medical expenditure.

- There was a dose-response relationship between use of metformin and reduced postoperative adverse events.

How might these results change the focus of research or clinical practice?

- Whether the association between metformin use and reduced risk is causal remains to be explored in future studies.

have become an important public health concern.

Metformin, a first-line therapeutic agent among newly diagnosed patients with diabetes, is attracting attention as a new supportive therapy against a variety of diseases, such as cancer, ${ }^{3}{ }^{4}$ stroke, ${ }^{56}$ and infectious diseases. ${ }^{78}$ In the UK Prospective Diabetes Study, metformin use was associated with significant risk reductions for myocardial infarction and death at long-term follow-up. ${ }^{9}$ The use of metformin was also associated with a significant $24.0 \%$ reduction in all-cause mortality when used as a means of secondary prevention. ${ }^{10}$ Other studies have shown that metformin treatment improves poststroke angiogenesis and recovery and may have practical clinical use for stroke prevention. ${ }^{56}$ 
It was known that people with diabetes had more complications, higher mortality, and consumed more medical resources after surgery than people without diabetes. ${ }^{1112}$ The effects of metformin use on perioperative outcomes were not completely understood because there were several limitations in previous studies, such as small sample size, ${ }^{13} 14$ a focus on specific surgical procedures, ${ }^{13-15}$ inadequate control for confounding factors, ${ }^{15}$ and a lack of global assessment. ${ }^{13}{ }^{15}$ Using the real-world data of Taiwan's National Health Insurance, we conducted a retrospective cohort study to evaluate complications and in-hospital mortality after major surgical procedures in patients with diabetes who did and did not use metformin.

\section{METHODS}

\section{Source of data}

In this study, we used the real-world database of Taiwan's National Health Insurance program that was implemented in March 1995; this insurance program covers more than $99 \%$ of the population in Taiwan. The available information included all beneficiaries' medical services, including inpatient and outpatient demographic characteristics, physicians' primary and secondary diagnoses, treatment procedures, prescriptions, and medical expenditures. This database has been validated previously. ${ }^{16-23}$ According to regulations of Taiwan's Ministry of Health and Welfare, informed consent is not required because patient identifications were decoded and scrambled.

\section{Study design}

Among 3.6million surgical patients who underwent major inpatient surgeries in Taiwan from 2008 to 2013, we identified 476938 surgical patients with diabetes aged 20 years and 153943 of them had used metformin within 24 months prior to the index surgery. Among surgical patients with diabetes, each patient who used metformin was randomly matched to a surgical patient who did not use metformin, using a propensity score-matched pair procedure (case-control ratio, 1:1) to adjust for sociodemographics, volume of the hospital, types of surgery, types of anesthesia, medical conditions, and Charlson comorbidity index.

\section{Definition and criteria}

For appropriately identifying metformin users in this study, we defined people who visited medical care and received a physician's prescription for metformin under the coverage of Taiwan's Health Insurance Program. In this study, we defined major inpatient surgery as surgical procedures requiring general, epidural or spinal anesthesia and index surgery with hospitalization for $>1$ day. Low-income status was defined as having a low income within 2 years before surgery. According to the regulations from the Ministry of Health and Welfare in Taiwan, people with low-income status were qualified to have the registration fee and medical copayment waived when visiting outpatient, emergency, and inpatient medical care. The criterion of low income was defined by local city or county governments. For example, a person living in Taipei (the capital of Taiwan) with a monthly income of less than US\$500 (1 Taiwanese dollar is equal to US\$30.324) and immovable possessions with a value of less than US $\$ 244031$ per household was considered to have a low income. In Taiwan, there were 144863 lowincome households and 304470 low-income people in 2019. The definition of low income varies with urban and rural areas because of the local living conditions.

The International Classification of Diseases, Ninth Revision, Clinical Modification (ICD-9-CM) administration codes and physicians' primary diagnoses were used to identify diabetes (ICD-9-CM 250), coexisting medical conditions (within the preoperative 24 months) and postoperative complications (that occurred during the index admission) for surgical patients. ${ }^{1124}$ These medical conditions were determined from medical claims for the 24-month preoperative period and included hypertension (ICD-9-CM 401-405), mental disorders (ICD-9-CM 290-319), ischemic heart disease (ICD-9-CM 410-414), chronic obstructive pulmonary disease (ICD-9-CM 491, 492 and 496), hyperlipidemia (ICD-9-CM 272.0, 272.1 and 272.2), liver cirrhosis (ICD-9-CM 571.2, 571.5 and 571.6), heart failure (ICD-9-CM 428), alcohol-related illness, renal dialysis (administration codes D8 and D9), and Parkinson's disease (ICD-9-CM 332). We defined alcohol-related illnesses, including alcoholic psychoses (ICD-9-CM 291), alcohol dependence syndrome (ICD-9-CM 303), alcohol abuse (ICD-9-CM 305), alcoholic fatty liver (ICD-9-CM 571.0), acute alcoholic hepatitis (ICD-9-CM 571.1), alcoholic cirrhosis of the liver (ICD-9-CM 571.2), and alcoholic liver damage (ICD-9-CM 571.3). Postoperative complications included postoperative bleeding (ICD-9-CM 998.0, 998.1 and 998.2), pneumonia (ICD-9-CM 480-486), septicemia (ICD-9-CM 038 and 998.5), urinary tract infection (ICD-9-CM 599.0), deep wound infection (ICD-9-CM 958.3), stroke (ICD-9-CM 430-437), acute myocardial infarction (ICD-9-CM 410), acute renal failure (ICD-9-CM 584) and pulmonary embolism (ICD-9-CM 415).

In this study, we examine the number of surgical procedures in every hospital in 2008-2013 and then categorized the surgical volume of hospital into three groups: low (the lowest tertile of surgical volume), moderate (the second tertile of surgical volume), and high (the highest tertile of surgical volume). In the National Health Insurance Program, the coverage of payment included all physician specialties of outpatient care, inpatient care, and emergency care. During the 24-month period before the index surgery, diabetes and coexisting medical conditions were defined as patients had at least two visits of medical care with physician's primary diagnosis. The 30-day postoperative mortality was calculated as death occurred within 30 days after the time point of surgical procedure included the period of during and discharge of index surgical admission. The complications after surgery during the index surgical admission 
Table 1 Preoperative characteristics of diabetic patients with and without use of metformin after matching by propensity score

\begin{tabular}{|c|c|c|c|}
\hline & $\begin{array}{l}\text { No metformin } \\
(n=91356)\end{array}$ & $\begin{array}{l}\text { Metformin } \\
(n=91356)\end{array}$ & $P$ value \\
\hline Sex & n (\%) & n (\%) & 1.0000 \\
\hline Female & $47461(52.0)$ & $47461(52.0)$ & \\
\hline Male & 43895 (48.0) & $43895(48.0)$ & \\
\hline Age, years & & & 1.0000 \\
\hline 20-29 & $1326(1.5)$ & $1326(1.5)$ & \\
\hline $30-39$ & $4133(4.5)$ & $4133(4.5)$ & \\
\hline $40-49$ & $8871(9.7)$ & $8871(9.7)$ & \\
\hline $50-59$ & $21197(23.2)$ & $21197(23.2)$ & \\
\hline $60-69$ & 26132 (28.6) & 26132 (28.6) & \\
\hline $70-79$ & $21667(23.7)$ & 21667 (23.7) & \\
\hline$\geq 80$ & $8030(8.8)$ & $8030(8.8)$ & \\
\hline Low income & & & 1.0000 \\
\hline No & 90538 (99.1) & 90538 (99.1) & \\
\hline Yes & $818(0.9)$ & $818(0.9)$ & \\
\hline Volume of hospital & & & 1.0000 \\
\hline Low & 31044 (34.0) & 31044 (34.0) & \\
\hline Moderate & 30652 (33.6) & 30652 (33.6) & \\
\hline High & 29660 (32.5) & 29660 (32.5) & \\
\hline \multicolumn{4}{|l|}{ Medical conditions } \\
\hline Hypertension & 28901 (31.6) & 28901 (31.6) & 1.0000 \\
\hline Mental disorders & $12861(14.1)$ & $12861(14.1)$ & 1.0000 \\
\hline $\begin{array}{l}\text { Ischemic heart } \\
\text { disease }\end{array}$ & $8098(8.9)$ & $8098(8.9)$ & 1.0000 \\
\hline COPD & 3194 (3.5) & $3194(3.5)$ & 1.0000 \\
\hline Hyperlipidemia & $3929(4.3)$ & $3929(4.3)$ & 1.0000 \\
\hline Liver cirrhosis & 2082 (2.3) & $2082(2.3)$ & 1.0000 \\
\hline Heart failure & $929(1.0)$ & $929(1.0)$ & 1.0000 \\
\hline $\begin{array}{l}\text { Alcohol-related } \\
\text { illness }\end{array}$ & $1125(1.2)$ & $1125(1.2)$ & 1.0000 \\
\hline Renal dialysis & $448(0.5)$ & $448(0.5)$ & 1.0000 \\
\hline $\begin{array}{l}\text { Parkinson's } \\
\text { disease }\end{array}$ & $619(0.7)$ & $619(0.7)$ & 1.0000 \\
\hline $\mathrm{CCl}$ scores & & & 1.0000 \\
\hline 1 & $51380(56.2)$ & $51380(56.2)$ & \\
\hline 2 & 16406 (18.0) & 16406 (18.0) & \\
\hline 3 & 13109 (14.4) & 13109 (14.4) & \\
\hline$\geq 4$ & 10461 (11.5) & 10461 (11.5) & \\
\hline Types of surgery & & & 1.0000 \\
\hline Skin & $1040(1.1)$ & $1040(1.1)$ & \\
\hline Breast & $1046(1.1)$ & $1046(1.1)$ & \\
\hline Musculoskeletal & $32296(35.4)$ & $32296(35.4)$ & \\
\hline Respiratory & 2919 (3.2) & $2919(3.2)$ & \\
\hline Cardiovascular & $2181(2.4)$ & $2181(2.4)$ & \\
\hline Digestive & 20435 (22.4) & 20435 (22.4) & \\
\hline $\begin{array}{l}\text { Kidney, ureter, } \\
\text { bladder }\end{array}$ & 8354 (9.1) & $8354(9.1)$ & \\
\hline
\end{tabular}

Continued
Table 1 Continued

\begin{tabular}{|c|c|c|c|}
\hline & $\begin{array}{l}\text { No metformin } \\
(n=91356)\end{array}$ & $\begin{array}{l}\text { Metformin } \\
(n=91356)\end{array}$ & $\mathbf{P}$ value \\
\hline Obstetric surgery & $1792(2.0)$ & $1792(2.0)$ & \\
\hline Neurosurgery & 11949 (13.1) & 11949 (13.1) & \\
\hline Eye & $1161(1.3)$ & $1161(1.3)$ & \\
\hline Others & $8183(9.0)$ & $8183(9.0)$ & \\
\hline Types of anesthesia & & & 1.0000 \\
\hline General & $68144(74.6)$ & $68144(74.6)$ & \\
\hline Epidural or spinal & $23212(25.4)$ & $23212(25.4)$ & \\
\hline $\begin{array}{l}\text { Chronic kidney } \\
\text { disease }\end{array}$ & $1421(1.6)$ & $1421(1.6)$ & 1.0000 \\
\hline $\begin{array}{l}\text { Prior diabetes } \\
\text { hospitalization }\end{array}$ & $1062(1.2)$ & $1062(1.2)$ & 1.0000 \\
\hline $\begin{array}{l}\text { Inadequate control } \\
\text { for diabetes }\end{array}$ & 10487 (11.5) & 10487 (11.5) & 1.0000 \\
\hline $\begin{array}{l}\text { Diabetes-related } \\
\text { ketoacidosis }\end{array}$ & $100(0.1)$ & $100(0.1)$ & 1.0000 \\
\hline $\begin{array}{l}\text { Diabetes-related } \\
\text { coma }\end{array}$ & $123(0.1)$ & $123(0.1)$ & 1.0000 \\
\hline $\begin{array}{l}\text { Diabetes-related } \\
\text { renal manifestations }\end{array}$ & $6509(7.1)$ & $6509(7.1)$ & 1.0000 \\
\hline $\begin{array}{l}\text { Diabetes-related eye } \\
\text { involvement }\end{array}$ & $8570(9.4)$ & $8570(9.4)$ & 1.0000 \\
\hline $\begin{array}{l}\text { Diabetes-related } \\
\text { PCD }\end{array}$ & $1464(1.6)$ & $1464(1.6)$ & 1.0000 \\
\hline Type I diabetes & $309(0.3)$ & $309(0.3)$ & 1.0000 \\
\hline $\begin{array}{l}\text { Preoperative use of } \\
\text { insulin }\end{array}$ & $6773(7.4)$ & $6773(7.4)$ & 1.0000 \\
\hline
\end{tabular}

$\mathrm{CCl}$, Charlson comorbidity index; COPD, chronic obstructive pulmonary disease; PCD, peripheral circulatory disorder.

were considered as secondary outcomes. The length of hospital stay (more than 1 day), medical expenditures (US dollars), and intensive care during the index surgical admission were also compared between patients who did and did not use metformin preoperatively.

\section{Statistical analysis}

We used a propensity score-matched pair design combined with frequency matching to balance the distribution of the covariates including age, sex, low income, volume of the hospital, types of surgery, types of anesthesia, hypertension, mental disorders, ischemic heart disease, chronic obstructive pulmonary disease, hyperlipidemia, liver cirrhosis, heart failure, alcohol-related illness, renal dialysis, Parkinson's disease, and Charlson comorbidity index between surgical patients who did and did not use metformin. For achieving a balance of covariates within matched pairs, we performed a structured iterative approach to refine this logistic regression model using 1:1 case-control match on the propensity score. We then matched (without replacement) patients who had metformin with those who did not by using a greedy matching algorithm. The algorithm proceeds 
sequentially to the lowest digit match on propensity score (one digit). This will be referred to as the 8-1 digit match.

Categorical variables were summarized using frequencies (percentages) and were compared between patients with diabetes who did and did not use metformin using the $\chi^{2}$ test. Continuous variables were summarized using means $\pm \mathrm{SD}$ and were compared using t-tests. Adjusted ORs and $95 \%$ CIs of postoperative complications, intensive care, and mortality associated with metformin use were calculated by multiple logistic regressions. Additional subgroup analyses stratified by age, sex, and number of medical conditions were also performed to examine the surgical outcomes among metformin recipients within these strata.

\section{RESULTS}

Under the propensity score-matching procedure, table 1 shows the balance in age, sex, low income, volume of the hospital, types of surgery, types of anesthesia, hypertension, mental disorders, ischemic heart disease, chronic obstructive pulmonary disease, hyperlipidemia, liver cirrhosis, heart failure, alcohol-related illness, renal dialysis, Parkinson's disease, and Charlson comorbidity index between surgical patients who did and did not use metformin. The characteristics of surgical patients with diabetes before matching procedure were shown in online supplemental table S1.

After adjustment in multiple logistic regression (table 2), patients with diabetes who used metformin had a lower risk of septicemia (OR $0.94,95 \%$ CI 0.90 to 0.98 ), acute renal failure (OR $0.87,95 \%$ CI 0.79 to 0.96 ), and 30-day mortality (OR $0.79,95 \%$ CI 0.71 to 0.88 ) than did the control group. The use of metformin was associated with a decreased risk of intensive care use after surgery (OR $0.60,95 \%$ CI 0.59 to 0.62 ). Lower medical expenditures $(1974 \pm 3887$ vs $2737 \pm 4200$ US $\$, p<0.0001)$ were also noted for patients with diabetes who used metformin than for those who did not use metformin.

In the stratified analysis (table 3 ), a reduced risk of postoperative adverse events (including postoperative pneumonia, septicemia, acute renal failure, stroke, intensive care and mortality) was associated with metformin use in subgroups of females (OR $0.68,95 \%$ CI 0.65 to 0.70 ), males (OR $0.65,95 \%$ CI 0.63 to 0.67 ) and patients with every age group. The association between metformin and reduced risk of postoperative adverse events was significant in patients with medical conditions $(0,1,2$, and $\geq 3$ ), Charlson comorbidity index (1, 2, 3, and $\geq 4$ scores), various types of surgeries and those received general anesthesia or epidural/spinal anesthesia.

In table 4, metformin users with chronic kidney disease (OR $0.85,95 \%$ CI 0.74 to 0.97 ), prior diabetes hospitalization (OR $0.66,95 \%$ CI 0.57 to 0.77 ), inadequate control for diabetes (OR $0.63,95 \%$ CI 0.60 to 0.67 ), diabetesrelated ketoacidosis (OR 0.80 , 95\% CI 0.49 to 1.29 ), renal manifestations (OR $0.60,95 \%$ CI 0.56 to 0.64 ), eye involvement (OR $0.56,95 \%$ CI 0.53 to 0.59 ), and peripheral circulatory disorder (OR $0.58,95 \%$ CI 0.50 to 0.67 ) had lower risks of postoperative adverse events compared with non-metformin control group. Patients with type 1 diabetes who used metformin also had reduced risk of postoperative adverse events (OR 0.62, 95\% CI 0.46 to 0.82). Compared with patients without use of metformin, the decreased risk of postoperative adverse events

Table 2 Use of metformin and postoperative outcomes in patients with diabetes

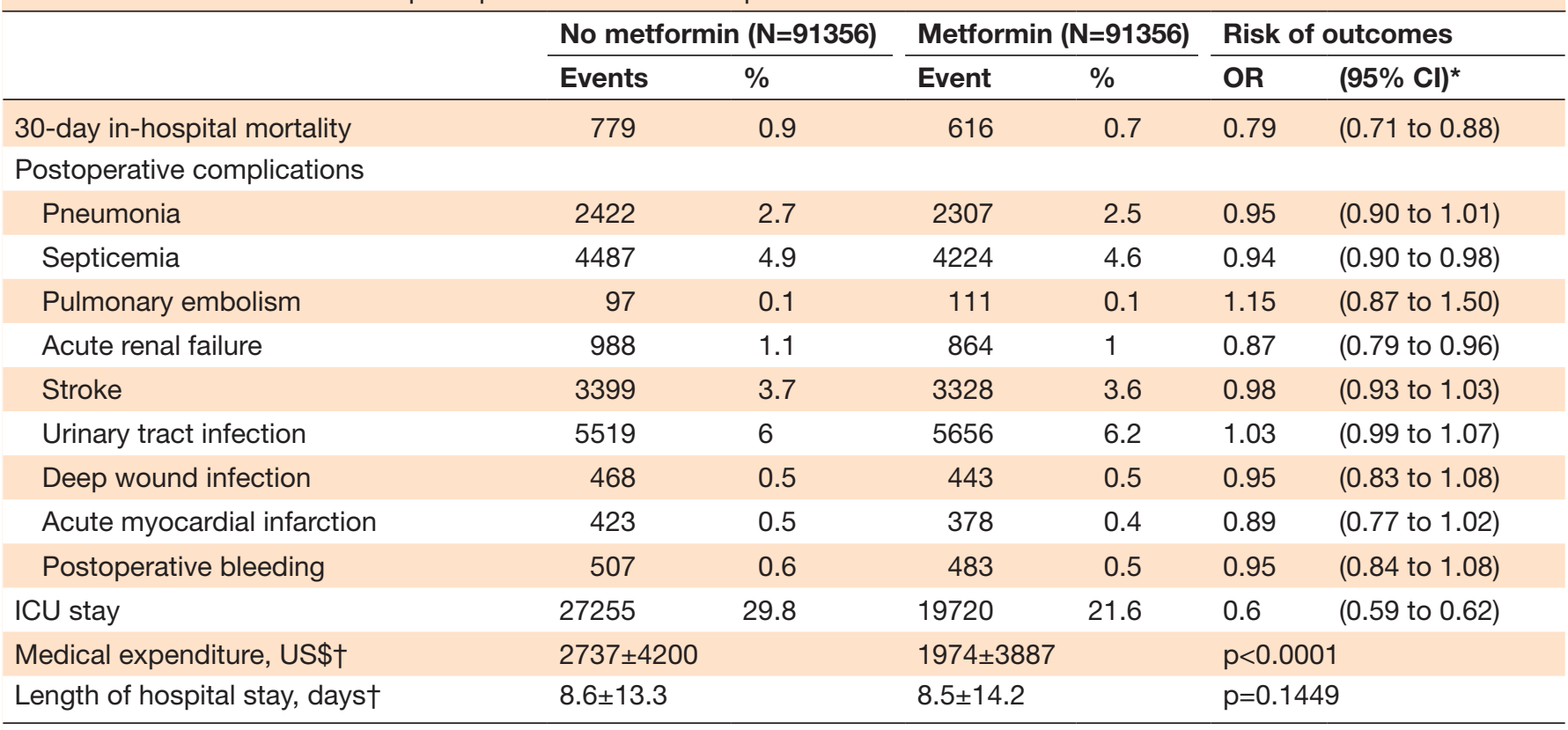

${ }^{*}$ Adjusted for all covariates listed in table 1.

†Mean \pm SD

ICU, intensive care unit. 
Table 3 The stratified analysis for postoperative adverse events associated with metformin use in patients with diabetes

\begin{tabular}{|c|c|c|c|c|c|c|}
\hline & & & Advers & vents ${ }^{*}$ & & \\
\hline & & $\mathbf{n}$ & Events & Rate, $\%$ & OR & (95\% Cl)† \\
\hline Female & No metformin & 47461 & 13398 & 28.2 & 1 & (reference) \\
\hline & Metformin & 47461 & 10356 & 21.8 & 0.68 & (0.65 to 0.70 ) \\
\hline Male & No metformin & 43895 & 15979 & 36.4 & 1 & (reference) \\
\hline & Metformin & 43895 & 12432 & 28.3 & 0.65 & (0.63 to 0.67 ) \\
\hline Age 20-39 years & No metformin & 5459 & 1270 & 23.3 & 1 & (reference) \\
\hline & Metformin & 5459 & 1172 & 21.5 & 0.89 & (0.81 to 0.98 ) \\
\hline Age $40-49$ years & No metformin & 8871 & 2497 & 28.2 & 1 & (reference) \\
\hline & Metformin & 8871 & 2286 & 25.8 & 0.87 & (0.81 to 0.94 ) \\
\hline Age $50-59$ years & No metformin & 21197 & 6527 & 30.8 & 1 & (reference) \\
\hline & Metformin & 21197 & 5333 & 25.2 & 0.73 & (0.70 to 0.76$)$ \\
\hline Age 60-69 years & No metformin & 26132 & 8391 & 32.1 & 1 & (reference) \\
\hline & Metformin & 26132 & 6195 & 23.7 & 0.61 & (0.59 to 0.64 ) \\
\hline Age $70-79$ years & No metformin & 21667 & 7462 & 34.4 & 1 & (reference) \\
\hline & Metformin & 21667 & 5388 & 24.9 & 0.58 & (0.55 to 0.61$)$ \\
\hline Age $\geq 80$ years & No metformin & 8030 & 3230 & 40.2 & 1 & (reference) \\
\hline & Metformin & 8030 & 2414 & 30.1 & 0.58 & (0.54 to 0.63 ) \\
\hline 0 medical condition & No metformin & 44113 & 13488 & 30.6 & 1 & (reference) \\
\hline & Metformin & 44113 & 10596 & 24 & 0.69 & (0.66 to 0.71$)$ \\
\hline 1 medical condition & No metformin & 34599 & 11311 & 32.7 & 1 & (reference) \\
\hline & Metformin & 34599 & 8619 & 24.9 & 0.64 & (0.62 to 0.67$)$ \\
\hline 2 medical conditions & No metformin & 10556 & 3775 & 35.8 & 1 & (reference) \\
\hline & Metformin & 10556 & 2943 & 27.9 & 0.64 & (0.60 to 0.69$)$ \\
\hline$\geq 3$ medical conditions & No metformin & 2088 & 803 & 38.5 & 1 & (reference) \\
\hline & Metformin & 2088 & 630 & 30.2 & 0.63 & (0.55 to 0.73 ) \\
\hline $1 \mathrm{CCl}$ score & No metformin & 51380 & 14236 & 27.7 & 1 & (reference) \\
\hline & Metformin & 51380 & 10745 & 20.9 & 0.65 & (0.63 to 0.67$)$ \\
\hline $2 \mathrm{CCl}$ scores & No metformin & 16406 & 5530 & 33.7 & 1 & (reference) \\
\hline & Metformin & 16406 & 4538 & 27.7 & 0.72 & (0.69 to 0.76$)$ \\
\hline $3 \mathrm{CCl}$ scores & No metformin & 13109 & 4770 & 36.4 & 1 & (reference) \\
\hline & Metformin & 13109 & 3459 & 26.4 & 0.59 & (0.56 to 0.62$)$ \\
\hline$\geq 4 \mathrm{CCl}$ scores & No metformin & 10461 & 4841 & 46.3 & 1 & (reference) \\
\hline & Metformin & 10461 & 4046 & 38.7 & 0.71 & (0.67 to 0.75$)$ \\
\hline Skin surgery & No metformin & 1040 & 402 & 38.7 & 1 & (reference) \\
\hline & Metformin & 1040 & 334 & 32.1 & 0.74 & (0.61 to 0.89$)$ \\
\hline Breast surgery & No metformin & 1046 & 327 & 31.3 & 1 & (reference) \\
\hline & Metformin & 1046 & 269 & 25.7 & 0.75 & (0.61 to 0.91$)$ \\
\hline Musculoskeletal surgery & No metformin & 32296 & 6128 & 19 & 1 & (reference) \\
\hline & Metformin & 32296 & 4696 & 14.5 & 0.71 & (0.68 to 0.74$)$ \\
\hline Respiratory surgery & No metformin & 2919 & 1180 & 40.4 & 1 & (reference) \\
\hline & Metformin & 2919 & 907 & 31.1 & 0.65 & (0.58 to 0.72$)$ \\
\hline Cardiovascular surgery & No metformin & 2181 & 1809 & 82.9 & 1 & (reference) \\
\hline & Metformin & 2181 & 1384 & 63.5 & 0.33 & (0.28 to 0.38$)$ \\
\hline Digestive surgery & No metformin & 20435 & 8771 & 42.9 & 1 & (reference) \\
\hline & Metformin & 20435 & 6881 & 33.7 & 0.65 & (0.63 to 0.68$)$ \\
\hline
\end{tabular}




政

Table 3 Continued

\begin{tabular}{|c|c|c|c|c|c|c|}
\hline & & & Advers & vents $^{*}$ & & \\
\hline & & $\mathbf{n}$ & Events & Rate, \% & OR & (95\% Cl)† \\
\hline Kidney, ureter, bladder surgery & No metformin & 8354 & 2411 & 28.9 & 1 & (reference) \\
\hline & Metformin & 8354 & 2015 & 24.1 & 0.78 & (0.72 to 0.83$)$ \\
\hline Obstetric surgery & No metformin & 1792 & 176 & 9.8 & 1 & (reference) \\
\hline & Metformin & 1792 & 206 & 11.5 & 1.21 & (0.97 to 1.50$)$ \\
\hline Neurosurgery surgery & No metformin & 11949 & 5954 & 49.8 & 1 & (reference) \\
\hline & Metformin & 11949 & 4217 & 35.3 & 0.52 & (0.49 to 0.55$)$ \\
\hline Eye surgery & No metformin & 1161 & 271 & 23.3 & 1 & (reference) \\
\hline & Metformin & 1161 & 204 & 17.6 & 0.69 & (0.57 to 0.85$)$ \\
\hline Others surgery & No metformin & 8183 & 1948 & 23.8 & 1 & (reference) \\
\hline & Metformin & 8183 & 1675 & 20.5 & 0.81 & (0.75 to 0.88$)$ \\
\hline Epidural or spinal anesthesia & No metformin & 23212 & 3726 & 16.1 & 1 & (reference) \\
\hline & Metformin & 23212 & 2979 & 12.8 & 0.76 & (0.72 to 0.80$)$ \\
\hline General anesthesia & No metformin & 68144 & 25651 & 37.6 & 1 & (reference) \\
\hline & Metformin & 68144 & 19809 & 29.1 & 0.64 & (0.63 to 0.66$)$ \\
\hline
\end{tabular}

*Adverse events included with 30-day in-hospital mortality, pneumonia, septicemia, acute renal failure, stroke, and intensive care. †Adjusted for all covariates listed in table 1.

$\mathrm{CCl}$, Charlson comorbidity index.

was also found in preoperative metformin users with (OR $0.75,95 \%$ CI 0.72 to 0.77 ) and without (OR 0.61, $95 \%$ CI 0.59 to 0.62 ) used metformin during the index surgical admission. Metformin users who had no preoperative insulin had lower risk of postoperative adverse events than the non-metformin control group (OR 0.63, $95 \%$ CI 0.62 to 0.65 ). However, the risk of postoperative adverse event was higher in metformin users who had preoperative insulin than in the non-metformin control group. There is a significant dose-response relationship between cumulative use of metformin and postoperative adverse event.

\section{DISCUSSION}

This is the first study to comprehensively evaluate the risks of complications and mortality after major surgery in patients who use metformin. Under a matching procedure by propensity score, we found that patients with diabetes who used metformin were more likely to have lower rates of postoperative stroke, pneumonia, sepsis, acute renal failure, and 30-day mortality compared with those who did not use metformin. Reduced use of the intensive care unit, length of hospital stay, and medical expenditure were also found more often in the metformin group compared with the non-metformin group.

Prior research has shown that metformin treatment was associated with a $15 \%$ decrease in all-cause mortality compared with insulin treatment in patients with diabetes undergoing colorectal surgery. ${ }^{25}$ Some studies also found that patients who used metformin had decreased 30-day mortality compared with non-users after ICU admission. ${ }^{26}$ However, the association between metformin use and mortality in patients with diabetes remains controversial. Various studies have found that the outcomes of septic patients who use metformin were not significantly different from those who did not use metformin. ${ }^{27} 28$ The possible cause for metformin reducing the mortality of patients with diabetes remains unclear. Earlier experimental studies showed that metformin might ameliorate sepsis or endotoxemia-associated lung injuries in many inflammatory diseases. ${ }^{29}$ It was suggested that metformin inhibits mitochondrial complex I, which plays an important role in modulating Toll-like receptor 4-mediated neutrophil activation, thus preventing acute inflammatory processes. ${ }^{30}$

In this study, we failed to investigate the association between metformin use and reduced risk of postoperative stroke. Previous studies have shown that metformin use in patients with diabetes might have a neuroprotective effect and was associated with a reduced incidence of stroke and neurological severity. ${ }^{531}$ The mechanisms underlying reductions in stroke severity in patients treated with metformin remain speculative and are likely multifactorial. Metformin is known to be a glucoselowering agent with actions mediated by the activation of adenosine $5^{\prime}$-monophosphate-activated protein kinase. ${ }^{32}$ Metformin possesses a direct scavenging effect against oxygenated free radicals generated in vitro ${ }^{33}$ and decreases intracellular production of reactive oxygen species in aortic endothelial cells. ${ }^{34}$ Various studies have reported that adenosine $5^{\prime}$-monophosphate-activated protein kinase signaling is associated with stimulation of vascular endothelial growth factor expression, angiogenesis in response to hypoxic stress, inhibition of the 
Table 4 Postoperative adverse events in association with the severity of patients with diabetes who used metformin

\begin{tabular}{|c|c|c|c|c|c|}
\hline & \multicolumn{5}{|c|}{ Adverse event* ${ }^{\star}$} \\
\hline & $\mathbf{n}$ & Events & Rate, \% & OR & $(95 \% \mathrm{Cl}) \dagger$ \\
\hline Non-metformin control group & 91356 & 29377 & 32.2 & 1 & (reference) \\
\hline \multicolumn{6}{|l|}{ Preoperative metformin users had } \\
\hline Chronic kidney disease & 1421 & 555 & 39.1 & 0.85 & (0.74 to 0.97$)$ \\
\hline Prior diabetes hospitalization & 1062 & 292 & 27.5 & 0.66 & (0.57 to 0.77$)$ \\
\hline Inadequate control for diabetes & 10487 & 2477 & 23.6 & 0.63 & (0.60 to 0.67$)$ \\
\hline Diabetes-related ketoacidosis & 100 & 26 & 26 & 0.8 & (0.49 to 1.29$)$ \\
\hline Diabetes-related coma & 123 & 43 & 35 & 1.12 & (0.74 to 1.69$)$ \\
\hline Diabetes-related renal manifestations & 6509 & 1508 & 23.2 & 0.6 & (0.56 to 0.64$)$ \\
\hline Diabetes-related eye involvement & 8570 & 1714 & 20 & 0.56 & (0.53 to 0.59$)$ \\
\hline Diabetes-related PCD & 1464 & 289 & 19.7 & 0.58 & (0.50 to 0.67$)$ \\
\hline Type I diabetes & 309 & 65 & 21 & 0.62 & (0.46 to 0.82$)$ \\
\hline No use of metformin in index admission & 54959 & 11602 & 21.1 & 0.61 & (0.59 to 0.62$)$ \\
\hline Used metformin in index admission & 36397 & 11186 & 30.7 & 0.75 & (0.72 to 0.77$)$ \\
\hline No preoperative use of insulin & 84583 & 19859 & 23.5 & 0.63 & (0.62 to 0.65$)$ \\
\hline Preoperative use of insulin & 6773 & 2929 & 43.3 & 1.12 & (1.06 to 1.18$)$ \\
\hline \multicolumn{6}{|l|}{ Cumulative use of metformin, DDD } \\
\hline$<50$ & 50360 & 15464 & 30.7 & 0.82 & (0.80 to 0.85$)$ \\
\hline $50-99$ & 13636 & 2718 & 19.9 & 0.53 & (0.50 to 0.55$)$ \\
\hline $100-149$ & 8199 & 1577 & 19.2 & 0.51 & (0.48 to 0.54$)$ \\
\hline $150-199$ & 6015 & 1041 & 17.3 & 0.47 & (0.43 to 0.50$)$ \\
\hline $200-249$ & 3426 & 616 & 18 & 0.49 & $(0.45$ to 0.54$)$ \\
\hline$\geq 250$ & 9720 & 1372 & 14.1 & 0.39 & (0.37 to 0.41$)$ \\
\hline
\end{tabular}

*Adverse events included with 30 day in-hospital mortality, pneumonia, septicemia, acute renal failure, stroke, and intensive care.

†Adjusted for all covariates listed in table 1.

DDD, daily defined dose; PCD, peripheral circulatory disorder.

inflammatory response, and protective effects against endothelial cell injury. ${ }^{35}{ }^{36}$ These various mechanisms may lead to reductions in cellular stress under hypoxia, thus protecting brain tissue from ischemic injury. As a result, future prospective studies may explore the assoication between metformin use and reduced risk of postoperative stroke.

The increased risk of infection after surgeries has been investigated in patients with diabetes. ${ }^{24} 37$ Recent studies have demonstrated that metformin use may reduce the infectious risk in patients with diabetes. ${ }^{7838}$ Metformin has several actions that cause it to mimic an antibiotic. Metformin is known to alter folate metabolism in certain bacteria by inhibiting the bacterial folate cycle. Its action was found to be similar to the antibiotic trimethoprim, which inhibits the enzyme dihydrofolate reductase. ${ }^{39}$ Previous research has shown that metformin inhibits complex 1 of the electron transport chain in mitochondria, ${ }^{40}$ which is structurally similar to the proton translocating unit of the bacterial respiratory chain complex. Hence, metformin has the potential to inhibit the energygenerating process in bacteria, which will result in inhibition of growth in bacteria. Metformin is also known to inhibit the bacterial mitochondrial enzyme glycerophosphate dehydrogenase, ${ }^{41}$ which will further prevent the utilization of glycerol and subsequent generation of ATP. This is expected to inhibit the growth of bacteria dependent on glycerol for their growth and virulence, such as Streptococcus pneumoniae and Mycoplasma pneumoniae. ${ }^{42}$ In the present study, we found that metformin use in patients with diabetes was associated with a reduced risk of postoperative pneumonia. However, the biomedical mechanism of the association between metformin and decreased risk of postoperative pneumonia requires further experimental research.

In the present study, we found that metformin use was associated with a significantly reduced risk of postoperative acute renal failure. Previous experimental studies have demonstrated the nephroprotective effect of metformin. ${ }^{43} 44$ The authors suggested that metformin activates adenosine 5'-monophosphateactivated protein kinase signaling and modulates other signaling pathways, including inhibition of mitochondrial reactive oxygen species generation, inhibition of mitochondrial respiratory chain complex I, reduction of renal lipotoxicity, and reduction of hypoxia inducible 
factor, thus protecting renal cells from damage. ${ }^{45}$ The therapeutic use of metformin in kidney disease was restricted by the US Food and Drug Administration due to the risk of patients developing lactic acidosis after its administration. However, more studies have indicated a relatively low incidence of lactic acidosis and revealed the additional benefits of metformin therapy. ${ }^{46}$ Hence, the US Food and Drug Administration has recently approved the use of metformin in patients with underlying kidney disease based on their estimated glomerular filtration rate. Its nephroprotective properties warrant additional studies to evaluate its effect as a nephroprotectant in patients with and without chronic kidney disease.

Although our study had several strengths, such as a large sample size, comprehensive matching by propensity score, global assessment of postoperative outcomes, including various types of surgery, and multivariate adjustment, some limitations need to be considered when interpreting our findings. First, we used administrative claims data that lacked detailed information on sociodemographic factors and lifestyle. Unmeasured confounding due to a combination of various factors, such as those related to unhealthy lifestyle and less social support, might have influenced the risk of outcomes. Second, we had no clinical data on various organ systems. The severity of disease and comorbid medical conditions could not be validated. The severity of kidney disease could have an impact on the prescription of metformin, as most metformin users could have mild kidney disease. The beneficial effect of metformin on postoperative acute renal failure could have been biased. The information of stage of chronic kidney disease and estimated glomerular filtration rate is not available in this database. Third, although the accuracy of the diagnosis codes from the research database in studies based on these codes has been accepted by peer reviewers for prominent scientific journals worldwide, the validity of diabetes, other comorbidities and complication codes might still be a limitation of this study. Fourth, we have to emphasize that a physician's prescription is not equal to a patient's intake because patient non-compliance commonly occurs in non-clinical settings. We also could not exclude the possibility that the results of this study were confounded by indication of metformin. In addition, the impact of characteristics of physician and hospital could not be controlled, although we adjusted the volume of hospital in this study. Finally, although we used multivariate adjustment to control for confounders, residual confounding is always possible.

In conclusion, metformin use was associated with a reduced risk of 30-day in-hospital mortality and postoperative complications, including pneumonia, septicemia, acute renal failure, and stroke. However, the beneficial effects of metformin on postoperative outcome should be validated in future randomized clinical trials to provide more evidence.
Author affiliations

${ }^{1}$ Department of Anesthesiology, Taipei Medical University Hospital, Taipei, Taiwan ${ }^{2}$ Anesthesiology and Health Policy Research Center, Taipei Medical University Hospital, Taipei, Taiwan

${ }^{3}$ Department of Anesthesiology, School of Medicine, College of Medicine, Taipei Medical University, Taipei, Taiwan

${ }^{4}$ Department of Surgery, China Medical University Hospital, Taichung, Taiwan

${ }^{5}$ Department of Surgery, University of Illinois, Chicago, Illinois, USA

${ }^{6}$ Division of Endocrinology, Department of Internal Medicine, National Taiwan University Hospital, Taipei, Taiwan

${ }^{7}$ Department of Anesthesiology, Wan Fang Hospital, Taipei Medical University, Taipei, Taiwan

${ }^{8}$ Research Center of Big Data and Meta-Analysis, Wan Fang Hospital, Taipei Medical University, Taipei, Taiwan

${ }^{9}$ School of Chinese Medicine, College of Chinese Medicine, China Medical University, Taichung, Taiwan

Acknowledgements This study is based on data obtained from Health and Welfare Information Science Center, Ministry of Health and Welfare, Taiwan. The interpretation and conclusions in this paper do not represent Ministry of Health and Welfare, Taiwan.

Contributors All authors participated in study design, interpretation of the data, and revising important intellectual improvement. C-SL and C-CL wrote the paper. $\mathrm{C}-\mathrm{CL}$ analyzed the data. T-LC has equal contribution with the corresponding author. All authors read and approved the final manuscript.

Funding This study was supported in part by The Higher Education Sprout Project by the Ministry of Education (DP2-109-21121-01-N-08-04) and Taiwan's Ministry of Science and Technology (MOST109-2221-E-038-003-MY2; MOST1082221-E-038-006; MOST106-2314-B-038-036-MY3).

Competing interests None declared.

Patient consent for publication Not required.

Ethics approval According to regulations of Taiwan's Ministry of Health and Welfare, informed consent is not required because patient identifications were decoded and scrambled. This study was approved by the institutional review board of Taipei Medical University (TMU-JIRB-201912046; TMU-JIRB-201801059; TMU-JIRB-201701050).

Provenance and peer review Not commissioned; externally peer reviewed.

Data availability statement Data may be obtained from a third party and are not publicly available. All data relevant to the study are included in the article.

Open access This is an open access article distributed in accordance with the Creative Commons Attribution Non Commercial (CC BY-NC 4.0) license, which permits others to distribute, remix, adapt, build upon this work non-commercially, and license their derivative works on different terms, provided the original work is properly cited, appropriate credit is given, any changes made indicated, and the use is non-commercial. See: http://creativecommons.org/licenses/by-nc/4.0/.

ORCID ID

Chien-Chang Liao http://orcid.org/0000-0001-6694-0730

\section{REFERENCES}

1 Squires E, Duber H, Campbell M, et al. Health care spending on diabetes in the U.S., 1996-2013. Diabetes Care 2018;41:1423-31.

2 Harding JL, Pavkov ME, Magliano DJ, et al. Global trends in diabetes complications: a review of current evidence. Diabetologia 2019;62:3-16.

3 Sehdev A, Shih Y-CT, Vekhter B, et al. Metformin for primary colorectal cancer prevention in patients with diabetes: a casecontrol study in a US population. Cancer 2015;121:1071-8.

4 Farmer RE, Ford D, Forbes HJ, et al. Metformin and cancer in type 2 diabetes: a systematic review and comprehensive bias evaluation. Int J Epidemiol 2017;46:745-44.

5 Venna VR, Li J, Hammond MD, et al. Chronic metformin treatment improves post-stroke angiogenesis and recovery after experimental stroke. Eur J Neurosci 2014;39:2129-38.

6 Jiang T, Yu J-T, Zhu X-C, et al. Acute metformin preconditioning confers neuroprotection against focal cerebral ischaemia by pre-activation of AMPK-dependent autophagy. Br J Pharmacol 2014;171:3146-57. 
7 Kajiwara C, Kusaka Y, Kimura S, et al. Metformin Mediates Protection against Legionella Pneumonia through Activation of AMPK and Mitochondrial Reactive Oxygen Species. J Immunol 2018;200:623-31.

8 Magee MJ, Salindri AD, Kornfeld H, et al. Reduced prevalence of latent tuberculosis infection in diabetes patients using metformin and statins. Eur Respir J 2019;53:1801695.

9 Holman RR, Paul SK, Bethel MA, et al. 10-Year follow-up of intensive glucose control in type 2 diabetes. N Engl J Med 2008;359:1577-89.

10 Roussel R, Travert F, Pasquet B, et al. Metformin use and mortality among patients with diabetes and atherothrombosis. Arch Intern Med 2010;170:1892-9.

11 Yeh C-C, Liao C-C, Chang Y-C, et al. Adverse outcomes after noncardiac surgery in patients with diabetes: a nationwide population-based retrospective cohort study. Diabetes Care 2013;36:3216-21.

12 Frisch A, Chandra P, Smiley D, et al. Prevalence and clinical outcome of hyperglycemia in the perioperative period in noncardiac surgery. Diabetes Care 2010;33:1783-8.

13 El Messaoudi S, Nederlof R, Zuurbier CJ, et al. Effect of metformin pretreatment on myocardial injury during coronary artery bypass surgery in patients without diabetes (MetCAB): a doubleblind, randomised controlled trial. Lancet Diabetes Endocrinol 2015;3:615-23.

14 Nayan M, Finelli A, Jewett MAS, et al. Metformin use and kidney cancer outcomes in patients with diabetes: a propensity score analysis. Clin Genitourin Cancer 2017;15:300-5.

15 Fransgaard T, Thygesen LC, Gögenur I. Association between metformin use after surgery for colorectal cancer and oncological outcomes: a nationwide register-based study. Int J Cancer 2018;143:63-72

16 Cheng C-L, Lee C-H, Chen P-S, et al. Validation of acute myocardia infarction cases in the National health insurance research database in Taiwan. J Epidemiol 2014;24:500-7.

17 Chan C-L, Lin W, Yang N-P, et al. The association between the availability of ambulatory care and non-emergency treatment in emergency medicine departments: a comprehensive and nationwide validation. Health Policy 2013;110:271-9.

18 Cheng C-L, Kao Y-HY, Lin S-J, et al. Validation of the National health insurance research database with ischemic stroke cases in Taiwan. Pharmacoepidemiol Drug Saf 2011;20:236-42.

19 Cheng C-L, Chien H-C, Lee C-H, et al. Validity of in-hospital mortality data among patients with acute myocardial infarction or stroke in national health insurance research database in Taiwan. Int J Cardiol 2015;201:96-101.

20 Hsieh C-Y, Chen C-H, Li C-Y, et al. Validating the diagnosis of acute ischemic stroke in a national health insurance claims database. $J$ Formos Med Assoc 2015;114:254-9.

21 Lin L-Y, Warren-Gash C, Smeeth L, et al. Data resource profile: the National health insurance research database (NHIRD). Epidemiol Health 2018;40:e2018062.

22 Liao C-C, Lin C-S, Shih C-C, et al. Increased risk of fracture and postfracture adverse events in patients with diabetes: two nationwide population-based retrospective cohort studies. Diabetes Care 2014;37:2246-52.

23 Hsieh C-Y, Su C-C, Shao S-C, et al. Taiwan's National health insurance research database: past and future. Clin Epidemiol 2019;11:349-58.

24 Lin C-S, Chang C-C, Lee Y-W, et al. Adverse outcomes after major surgeries in patients with diabetes: a multicenter matched study. $J$ Clin Med 2019;8:100.

25 Fransgaard T, Thygesen LC, Gögenur I. Metformin increases overall survival in patients with diabetes undergoing surgery for colorectal cancer. Ann Surg Oncol 2016;23:1569-75.

26 Christiansen C, Johansen M, Christensen S, et al. Preadmission metformin use and mortality among intensive care patients with diabetes: a cohort study. Crit Care 2013;17:R192.
27 Jochmans S, Alphonsine J-E, Chelly J, et al. Does metformin exposure before ICU stay have any impact on patients' outcome? A retrospective cohort study of diabetic patients. Ann Intensive Care 2017;7:116.

28 van Vught LA, Scicluna BP, Hoogendijk AJ, et al. Association of diabetes and diabetes treatment with the host response in critically ill sepsis patients. Crit Care 2016;20:252.

$29 \mathrm{Kim}$ J, Kwak HJ, Cha J-Y, et al. Metformin suppresses lipopolysaccharide (LPS)-induced inflammatory response in murine macrophages via activating transcription factor-3 (ATF-3) induction. J Biol Chem 2014;289:23246-55.

30 Vaez H, Rameshrad M, Najafi M, et al. Cardioprotective effect of metformin in lipopolysaccharide-induced sepsis via suppression of Toll-like receptor 4 (TLR4) in heart. Eur J Pharmacol 2016;772:115-23.

31 Mima Y, Kuwashiro T, Yasaka M, et al. Impact of metformin on the severity and outcomes of acute ischemic stroke in patients with type 2 diabetes mellitus. J Stroke Cerebrovasc Dis 2016;25:436-46.

32 Zou M-H, Kirkpatrick SS, Davis BJ, et al. Activation of the AMPactivated protein kinase by the anti-diabetic drug metformin in vivo. Role of mitochondrial reactive nitrogen species. J Biol Chem 2004;279:43940-51.

33 Bonnefont-Rousselot D, Raji B, Walrand S, et al. An intracellular modulation of free radical production could contribute to the beneficial effects of metformin towards oxidative stress. Metabolism 2003;52:586-9

34 Ouslimani N, Peynet J, Bonnefont-Rousselot D, et al. Metformin decreases intracellular production of reactive oxygen species in aortic endothelial cells. Metabolism 2005;54:829-34.

35 Ouchi N, Shibata R, Walsh K. Amp-Activated protein kinase signaling stimulates VEGF expression and angiogenesis in skeletal muscle. Circ Res 2005;96:838-46.

36 Ouslimani N, Mahrouf M, Peynet J, et al. Metformin reduces endothelial cell expression of both the receptor for advanced glycation end products and lectin-like oxidized receptor 1. Metabolism 2007;56:308-13.

37 King JT, Goulet JL, Perkal MF, et al. Glycemic control and infections in patients with diabetes undergoing noncardiac surgery. Ann Surg 2011;253:158-65.

38 Courtois S, Bénéjat L, Izotte J, et al. Metformin can inhibit Helicobacter pylori growth. Future Microbiol 2018;13:1575-83.

39 Cabreiro F, Au C, Leung K-Y, et al. Metformin retards aging in C. elegans by altering microbial folate and methionine metabolism. Cell 2013;153:228-39.

40 Owen MR, Doran E, Halestrap AP. Evidence that metformin exerts its anti-diabetic effects through inhibition of complex 1 of the mitochondrial respiratory chain. Biochem J 2000;348 Pt 3:607-14.

41 Madiraju AK, Erion DM, Rahimi Y, et al. Metformin suppresses gluconeogenesis by inhibiting mitochondrial glycerophosphate dehydrogenase. Nature 2014;510:542-6.

42 Elkhal CK, Kean KM, Parsonage D, et al. Structure and proposed mechanism of L- $\alpha$-glycerophosphate oxidase from Mycoplasma pneumoniae. Febs J 2015;282:3030-42.

43 Ishibashi Y, Matsui T, Takeuchi M, et al. Beneficial effects of metformin and irbesartan on advanced glycation end products (AGEs)-RAGE-induced proximal tubular cell injury. Pharmacol Res 2012;65:297-302.

44 Morales Al, Detaille D, Prieto M, et al. Metformin prevents experimental gentamicin-induced nephropathy by a mitochondriadependent pathway. Kidney Int 2010;77:861-9.

45 Ravindran S, Kuruvilla V, Wilbur K, et al. Nephroprotective effects of metformin in diabetic nephropathy. J Cell Physiol 2017;232:731-42.

46 DeFronzo R, Fleming GA, Chen K, et al. Metformin-Associated lactic acidosis: current perspectives on causes and risk. Metabolism 2016;65:20-9. 